BERKALA FISIKA INDONESIA

\title{
Sistem akuisisi data percobaan pemanasan alkohol berbasis software plx-daq dan arduino uno
}

\author{
Mufid Eska Nurcahya ${ }^{1 *}$, Okimustava ${ }^{2}$ \\ 1,2 Pendidikan Fisika, Fakultas Keguruan dan Ilmu Pendidikan, Universitas Ahmad Dahlan, Indonesia \\ Email: mufid1600007039@webmail.uad.ac.id* \\ * Penulis korespondensi
}

\begin{tabular}{l}
\hline Informasi artikel \\
\hline Sejarah artikel: \\
Dikirim \\
Revisi \\
Diterima \\
\hline
\end{tabular}

\section{Kata kunci:}

Arduino uno

Kalor jenis alkohol

PLX-DAQ

Sensor LM35

Sistem akuisisi data

\section{Keywords:}

Arduino uno

Specific heat of alcohol

PLX-DAQ

LM35 sensor

Data acquisition system

\begin{abstract}
ABSTRAK
Penelitian ini bertujuan untuk merancang alat eksperimen untuk menguji suhu pemanasan pada alkohol. Software PLX-DAQ dan software arduino digunakan untuk membaca perangkat arduino uno. Software PLX-DAQ digunakan untuk menampilkan data yang berada pada perangkat arduino ke dalam excel. Pembuatan sensor LM35 anti air menggunakan heat shrink sebagai pelindung paling luar, lem epoxy yang tahan terhadap air. Kemudian sensor terhubung dengan arduino dan laptop yang diproses di dalam software PLX-DAQ. Dengan PLX-DAQ diperoleh sistem akuisisi data perubahan suhu alkohol dan didapatkan besar kalor jenis alkohol. Kalor jenis alkohol dengan sensor $L M 35$ yaitu $Q=67,968 \mathrm{~J} / \mathrm{kg}^{\circ} \mathrm{C}$, sedangkan dengan menggunakan termometer diperoleh $Q=68,880 \mathrm{~J} / \mathrm{kg}^{\circ} \mathrm{C}$. Sehingga persentase ralat yang diperoleh adalah $1,324 \%$. Simpulan pada penelitian ini adalah rancangan alat eksperimen sensor LM35 dapat digunakan untuk mengukur perubahan suhu pada pemanasan alkohol. Oleh karena itu, alat eksperimen yang dibuat dapat digunakan dalam pembelajaran fisika.
\end{abstract}

This is an open access article under the CC-BY-SA license

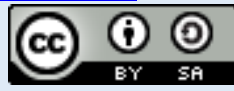

\section{ABSTRACT}

Data acquisition system for alcohol heating experiments based on plx-daq and arduino uno software. This study aims to design an experimental device to test the heating temperature of alcohol. PLX-DAQ software and Arduino software are used to read Arduino Uno devices. PLX-DAQ software is used to display data residing on Arduino devices in Excel. The manufacture of the LM35 waterproof sensor uses heat shrink as the outermost protection, epoxy glue that is resistant to water. Then the sensor is connected to the Arduino and the laptop, which is processed in the PLX-DAQ software. With PLX-DAQ obtained data acquisition system changes in temperature of alcohol and obtained the specific heat of alcohol. The specific heat of alcohol with the LM35 sensor is $Q=67.968 \mathrm{~J} / \mathrm{kg}^{\circ} \mathrm{C}$, while using a thermometer obtained $Q=68.880 \mathrm{~J} / \mathrm{kg}^{\circ} \mathrm{C}$. The percentage of errors obtained is $1.324 \%$. This study's conclusion is the design of the LM35 sensor experimental tool to measure temperature changes on heating alcohol. Therefore, the experimental tools made can be used in learning physics.

\section{How to Cite:}

Nurcahya, M. E., \& Okimustava. (2020). Sistem akuisisi data percobaan pemanasan alkohol berbasis software plx-daq dan arduino uno. Berkala Fisika Indonesia: Jurnal Ilmiah Fisika, Pembelajaran dan Aplikasinya, 11(1), 1-9. 


\section{Pendahuluan}

Kalor $(Q)$ suatu zat berbanding lurus dengan massa zat $(m)$, kalor jenis suatu zat $(c)$ dan perubahan suhu awal hingga akhir $(\Delta T)$. Semakin besar perubahan suhu suatu cairan maka kalor yang dihasilkan semakin besar (Ridhuan et al., 2019). Alkohol adalah senyawa larutan yang disebut etanol dan memiliki rumus kimia $\mathrm{C}_{2} \mathrm{H}_{5} \mathrm{OH}$, tetapi di lain sisi dapat digunakan untuk membersihkan luka atau digunakan dalam operasi di rumah sakit. Alkohol $(\mathrm{ROH})$ sangat penting dalam kehidupan sehari-hari. Banyak dari senyawa ini digunakan sebagai pelarut dan reagen di laboratorium dan manufaktur (Agustina, 2017; Novalina et al., 2015). Alkohol $\left(\mathrm{C}_{2} \mathrm{H}_{5} \mathrm{OH}\right)$ adalah cairan bening, tidak berwarna, bergerak, dan mudah menguap yang dapat bercampur dengan air, eter, kloroform dan dihasilkan melalui fermentasi ragi (Prihandana et al., 2007). Mikroorganisme memainkan peran penting dalam proses fermentasi, yang menghasilkan produksi alcohol (Azizah et al., 2012). Mikroorganisme yang digunakan untuk fermentasi biasanya memenuhi berbagai kriteria, termasuk memfermentasi gula yang sesuai dengan cepat, mengembangkan flokulasi dan sedimentasi (misalnya, sel ragi sering terdapat di dasar tangki fermentasi dan memiliki genetika yang sehat) (Berlian et al., 2016).

Sensor adalah sistem yang mendeteksi tanda atau sinyal yang disebabkan oleh pengubahan besaran fisik menjadi besaran listrik (Fraden, 2010; Mustar \& Wiyagi, 2017). Misalnya, besaran suhu menjadi tegangan listrik. LM35 adalah contoh perangkat elektronik yang dapat digunakan sebagai sensor suhu. LM35 menunjukkan linearitas antara suhu dan tegangan keluaran yang dihasilkan (Nurhayati, 2012). LM35 merupakan sensor suhu dengan keluaran Celcius yang dapat mendeteksi suhu antara 0 hingga 100 derajat Celcius (Rahayuningtyas et al., 2016). Tegangan keluaran sensor suhu LM35 berbanding lurus dengan suhu dalam derajat Celcius sebesar sepuluh $\mathrm{mV} /{ }^{\circ} \mathrm{C}$. Karena impedansi keluarannya yang rendah dan linieritasnya yang tinggi, LM35 mudah dipasang ke sirkuit kontrol khusus LM35 hanya membutuhkan arus $60 \mathrm{~A}$. Ini berarti LM35 akan menghasilkan panas dari sensor (SelfHeating), menghasilkan kesalahan pembacaan rendah kurang dari $0,5^{\circ} \mathrm{C}$ pada $25^{\circ} \mathrm{C}$ (Suoth et al., 2013).

Arduino Uno adalah alat prototipe elektronik perangkat keras yang bersifat open-source hardware. Keberhasilannya dibangun di atas perangkat keras dan aplikasi yang modular dan mudah digunakan. Terdapat 14 pin optik, 6 input analog, 1 osilator kristal 16 MHz, 1 link USB, 1 konektor sumber tegangan, 1 header ICSP, dan 1 tombol reset pada Arduino Uno (Sari \& Kirindi, 2019; Tambak \& Bahriun, 2015).

Energi termal yang dimiliki suatu bahan disebut kalor. Untuk mendeteksi panas yang terkandung oleh suatu benda secara umum yaitu dengan mengukur suhu benda tersebut. Sementara suhunya tinggi, jumlah panas yang disimpan oleh benda itu besar, dan bila suhunya rendah, jumlah panas yang dikandungnya kecil. Besarnya kalor yang dibutuhkan suatu benda (zat) ditentukan oleh massa zat, jenis zat (kalor jenis), dan perubahan suhu (Faizal \& Wahyudi, 2017; Santi, 2008)

Permasalahan eksperimen ini difokuskan pada akuisisi data pada larutan alkohol yang dipanaskan dan menghitung waktu yang dibutuhkan agar alkohol mendidih. Kelebihan dari eksperimen ini adalah 
memberi kita kesempatan untuk membuat alat yang sederhana tetapi bisa digunakan dengan mudah dan praktis dengan biaya yang rendah dan dapat digunakan untuk larutan yang ingin diukur suhunya, dan juga dengan akuisisi data software gratis tanpa biaya yaitu PLX-DAQ dan pengolah membaca sensor dengan software arduino, selanjutnya merancang alat percobaan untuk menguji sensor tersebut. Oleh karena itu, penelitian ini bertujuan merancang alat eksperimen untuk menguji suhu pemanasan pada alkohol. Didapatkan hasil suhu yang diukur setiap waktu. Eksperimen ini dilakukan untuk mengetahui sensor LM35 yang dibuat sedemikian rupa apakah memiliki akurasi yang sesuai dengan termometer.

\section{Metode}

Eksperiman ini untuk mencari akuisisi data setiap perubahan suhu alkohol. Eksperimen ini dilakukan untuk mengetahui sensor LM35 yang dibuat sedemikian rupa apakah memiliki akurasi yang sesuai dengan termometer, eksperimen tersebut dilakukan di Universitas Ahmad Dahlan kampus 3 yang dilakukan pada tanggal 26 Desember 2018. Yang pertama dilakukan yaitu menyiapkan arduino uno, sensor LM35, epoxy, selotip, gelas ukur, laptop, alat pemanas dan alkohol 1 liter. Dalam kenyataanya ada alat ukur suhu yang tahan terhadap air salah satunya seperti model DS18B20 yang lebih praktis dan lebih akurat. Namun dalam eksperimen ini menggunakan LM35 karena itu memungkinkan adanya pendekatan dengan suhu sebenarnya. Desain eksperimen ditampilkan dalam Gambar 1.

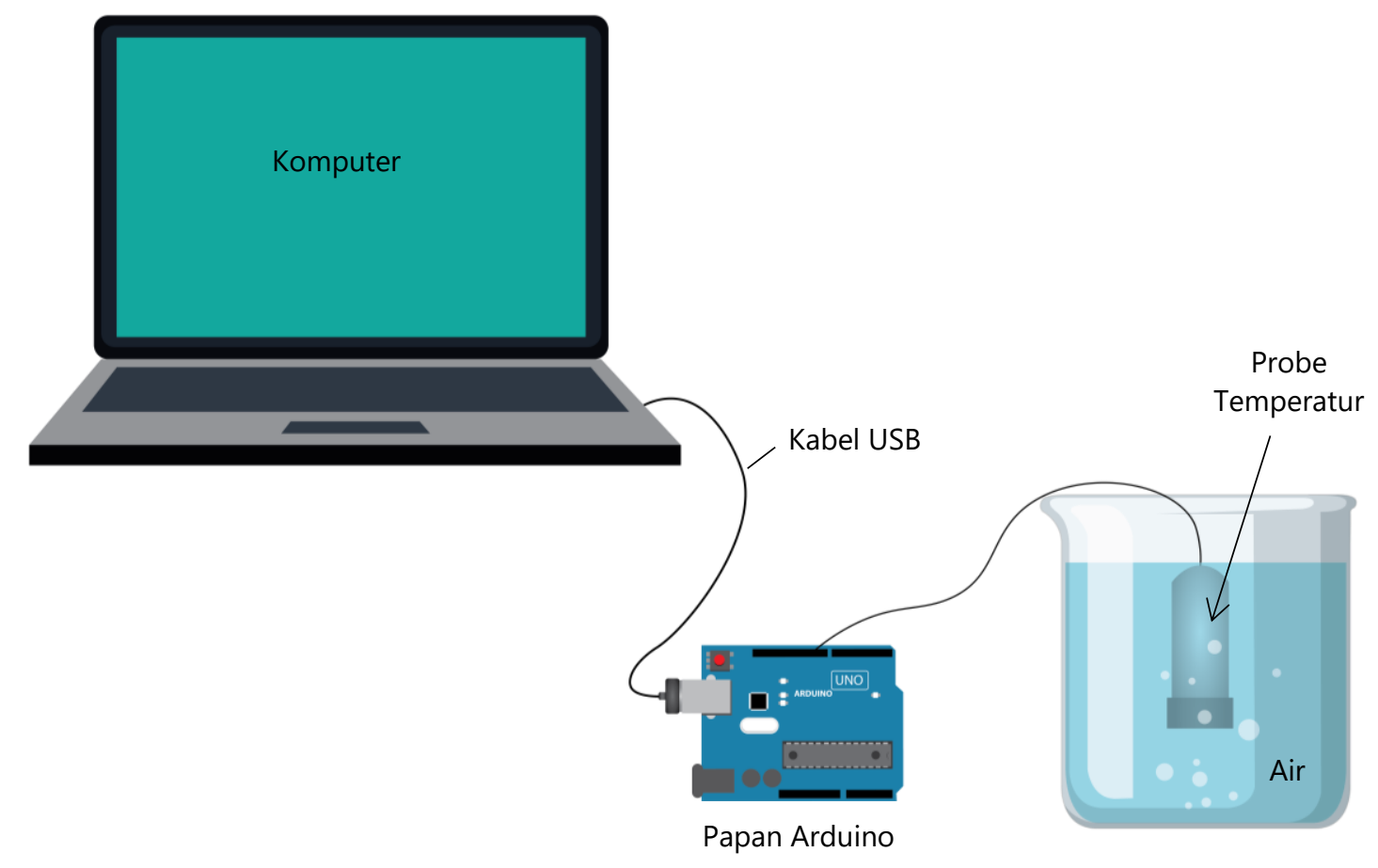

Gambar 1. Disain eksperimen

Pada Gambar 1 menunjukkan bahwa perakitan dengan merangkai kaki-kaki arduino dengan lapisan anti air dan badan sensor yang dilindungi dengan heat shrink agar tahan terhadap air. Langkah 
perakitan yang pertama menyambung kawat pada sensor dengan kabel yang berbeda warnanya, kemudian pisahkan kaki-kaki LM35 dengan sekat menggunakan alat penyekat untuk melindungi dari konsleting atau sirkuit pendek. Setelah itu tutup pin dengan lapisan dempul epoksi dan tunggu sampai mengering. Setelah itu meng-coding untuk arduino dan menghubungkan dengan LM35 supaya mudah untuk mengkalibrasinya dengan menyamakanya dengan termometer. Jika sudah maka menuangkan 1 liter alkohol ke dalam gelas ukur, kemudian menaruh probe sensor dan tancapkan alat pemanasnya. Gambar 2 merupakan sensor LM35 yang telah dirancang sehingga anti air.

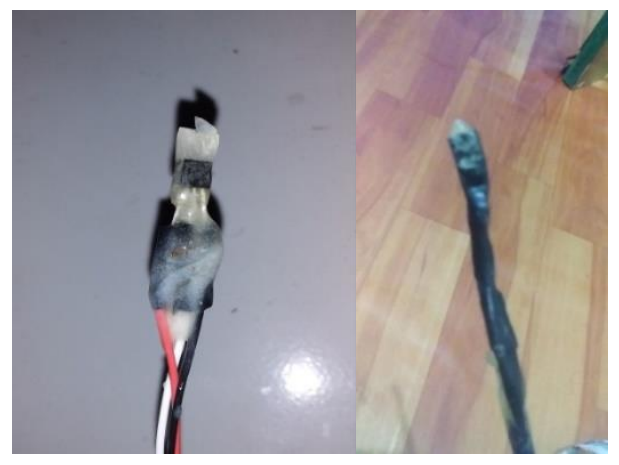

Gambar 2. Rangkaian anti air sensor LM35

Gambar 2 menunjukkan probe dirakit menutupi pin LM35 dengan lapisan dempul epoksi untuk melindunginya dari efek air. Langkah-langkah perakitan, yaitu: (1). Las pin sensor ke kabel dengan warna berbeda, (2). Tutup pin tengah sensor dan badan sensor dengan isolasi untuk melindungi dari korsleting dan kerusakan, (3). Tutup pin dengan lapisan dempul epoksi dan tunggu pengeringan epoksi. Pin tidak boleh berada dalam hubungan pendek. Sensor base adalah area perbatasan kecil dan membutuhkan perhatian khusus untuk menghindari kontak dengan epoksi, (4). Epoxy kering adalah insulator listrik, tetapi rentan terhadap infiltrasi air lambat yang dapat mengganggu operasi sensor jika beroperasi beberapa jam didalam air, (5). Berikan pelindung kabel agar lebih tahan air. Gambar 3 menunjukkan rangkaian alat eksperimen sistem akuisisi data pemanasan alkohol.

Langkah mengoperasikan PLX-DAQ yaitu: (1). Sensor LM35 menghasilkan listrik sinyal tegangan output sebanding dengan suhu, (2). Papan arduino menerima output sensor sinyal dan menghasilkan angka yang sebanding dengan temperatur alkohol. Perhatikan bahwa, jumlahnya juga sama atau mendekati dengan suhu yang diukur. Kemudian, arduino mengirimkan data ke komputer. (3). Komputer menerima data dan secara otomatis menunjukkan informasi dan memplotnya dalam excel berupa angka dan grafik suhu. (4). Mengatur software dengan menyamakan port yang sesuai dengan arduino dan mengatur waktu yang dibutuhkan untuk mengukur berapa lama perhitungan suhunya. Selanjutnya mengklik connect dan menyalakan alat pemanasnya. Setelah itu di excel akan menampilkan akuisisi data yang diperoleh. Gambar 4 merupakan contoh tampilan penggunaan software PLX-DAQ. 


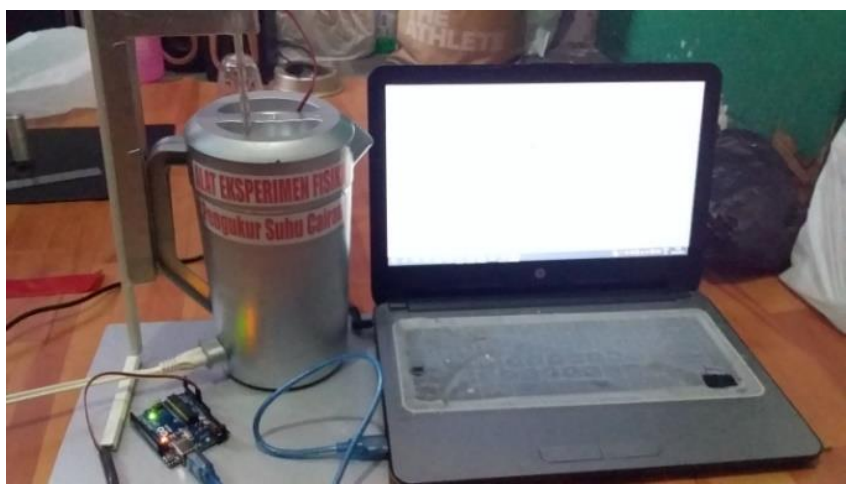

Gambar 3. Alat eksperimen

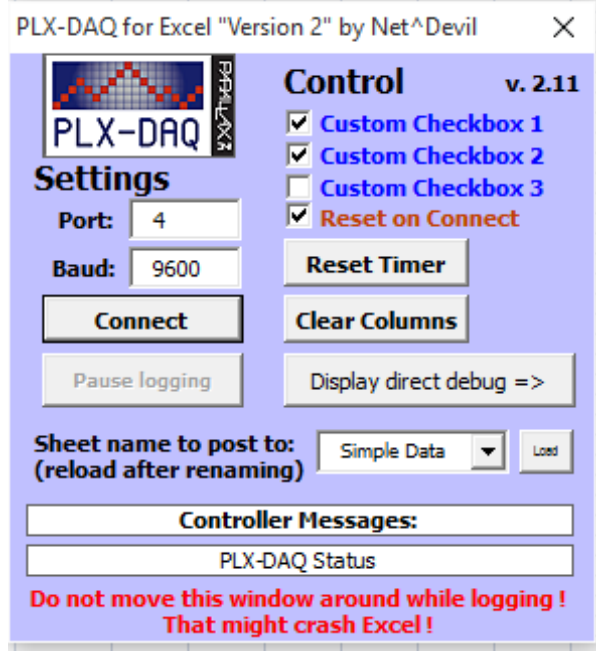

Gambar 4. Software PLX-DAC

\section{Hasil dan Pembahasan}

Dari eksperimen yang telah dilakukan dengan menghubungkan arduino dengan pc. Program telah dibuat dengan software PLX-DAQ yang hasil output nya berada pada Microsoft excel maka didapatkan hasil sebagaimana ditampilkan dalam Tabel 1.

Tabel 1. Akuisisi data pemanasan alkohol

\begin{tabular}{cccc}
\hline Waktu & Suhu $\left({ }^{\circ} \mathbf{C}\right)$ & Waktu & Suhu $\left({ }^{\circ} \mathbf{C}\right)$ \\
\hline 1,718750 & 33,71 & 76,546880 & 48,36 \\
6,531250 & 33,22 & 81,546880 & 49,33 \\
11,531250 & 34,19 & 86,546880 & 50,31 \\
16,531250 & 34,19 & 91,546880 & 51,28 \\
21,531250 & 35,66 & 96,546880 & 53,24 \\
26,531250 & 36,64 & 101,546900 & 54,21 \\
31,531250 & 37,61 & 106,546900 & 56,17 \\
36,531250 & 38,59 & 111,546900 & 57,14 \\
41,531250 & 39,57 & 116,562500 & 56,66 \\
46,531250 & 41,03 & 121,562500 & 58,12 \\
51,539060 & 42,5 & 126,562500 & 59,59 \\
56,546880 & 43,96 & 131,562500 & 60,07 \\
61,546880 & 43,96 & 136,562500 & 62,03 \\
66,546880 & 45,91 & 141,562500 & 62,03 \\
71,546880 & 47,38 & & \\
\hline
\end{tabular}


Dari Tabel 1, akuisisi data pemanasan alkohol hingga mendidih diperoleh 29 data yang dilakukan dengan rentang waktu 5 sekon. Setiap 5 sekon mengalami kenaikan $\pm 1{ }^{\circ} \mathrm{C}$. Sehingga dapat diperoleh $\Delta T=28,32{ }^{\circ} \mathrm{C}$. Gambar 5 menunjukkan grafik perubahan suhu pada proses pemanasan alkohol menggunakan sensor LM35. Pada Gambar 5, dapat dilihat perubahan suhu termometer pada saat dipanaskan hingga mendidih dengan menggunakan sensor LM35. Perubahan yang terjadi mendekati linier sehingga pembacaan sensor sudah cukup baik. Hal ini dibuktikan dengan nilai $R^{2}$ yang diperoleh sebesar 0,9947.

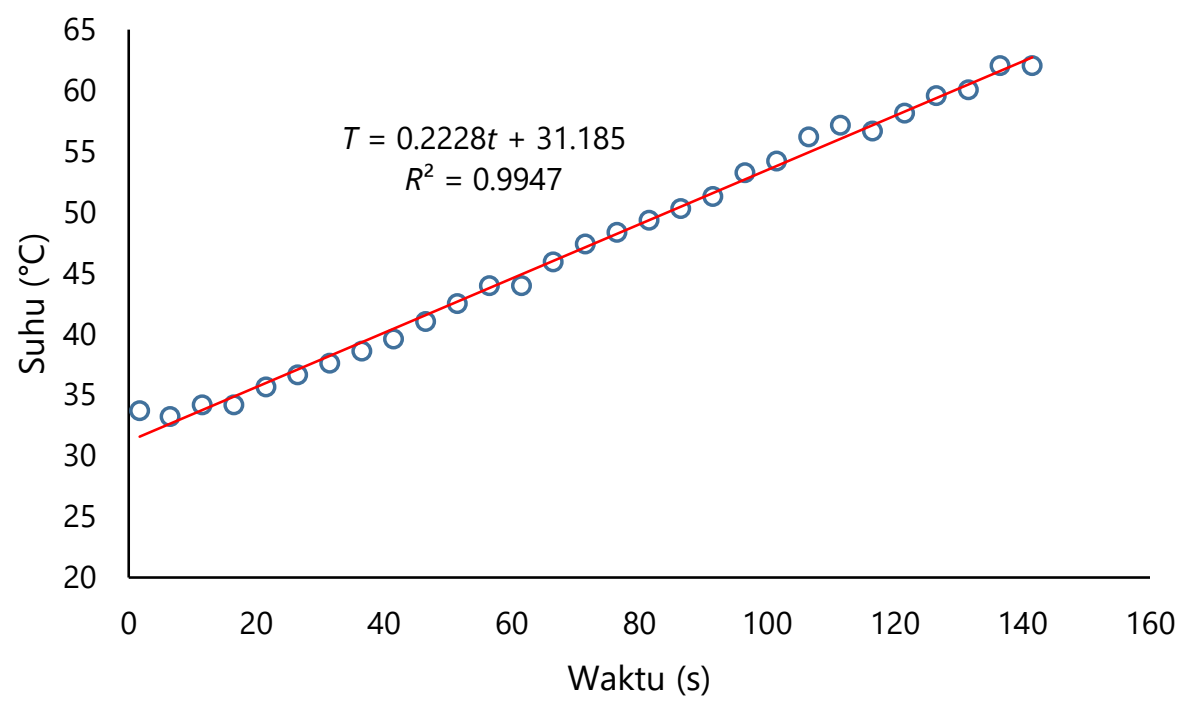

Gambar 5. Pemanasan alkohol dengan sensor LM35

Selanjutnya adalah melakukan perbandingan akuisisi data perubahan suhu menggunakan sensor LM35 dan termometer. Data luaran dari kedua alat ini ditampilkan dalam Tabel 2. Sedangkan Gambar 6 merupakan perbandingan linearitas luaran sensor LM35 dan termometer.

Pada Tabel 2 dan Gambar 6 diperoleh, selisih sensor LM35 yang cukup mendekati termometer dan perhitungan yang diperoleh yaitu kalor jenis alkokol dengan sensor LM35 $Q=67,968 \mathrm{~J} / \mathrm{Kg}^{\circ} \mathrm{C}$. Sedangkan dengan menggunakan termometer $Q=68,880 \mathrm{~J} / \mathrm{Kg}^{\circ} \mathrm{C}$. Kemudian waktu yang diperlukan untuk mendidihkan alkohol dalam eksperimen adalah 140 sekon, jika secara perhitungan dengan menggunakan sensor LM35 yaitu 135,936 sekon. Sedangkan dengan menggunakan termometer yaitu 137,76 sekon.

Berdasarkan eksperimen yang dilakukan dengan menggunakan software PLX-DAQ dengan menggunakan arduino sebagai pengolah data dari sensor diperoleh grafik linier yang dapat dilihat pada Gambar 6 di mana hal tersebut dapat menjelaskan bahwa sensor suhu LM35 yang dibuat menghasilkan perolehan data yang mendekati termometer. Sehingga dalam analisis perhitungan antara sensor LM35 dan termometer dilakukan dalam software Microsoft excel mendapatkan hasil yang bervariatif antara sensor LM35 dan termometer. Persentase ralat dari pengukuran masing-masing sensor dan termometer 
dapat diketahui melalui perolehan perhitungan kalor alkohol dengan sensor LM35 dan termometer alkohol.

Tabel 2. Nilai perubahan suhu sensor dan termometer

\begin{tabular}{|c|c|c|c|}
\hline \multicolumn{2}{|c|}{ LM35 } & \multicolumn{2}{|c|}{ Termometer } \\
\hline Waktu & Suhu (C) & Waktu & Suhu (C) \\
\hline 1,718750 & 33,71 & 0 & 34 \\
\hline 6,531250 & 33,22 & 5 & 34,5 \\
\hline 11,531250 & 34,19 & 10 & 35 \\
\hline 16,531250 & 34,19 & 15 & 36 \\
\hline 21,531250 & 35,66 & 20 & 37,5 \\
\hline 26,531250 & 36,64 & 25 & 39 \\
\hline 31,531250 & 37,61 & 30 & 40,1 \\
\hline 36,531250 & 38,59 & 35 & 41,1 \\
\hline 41,531250 & 39,57 & 40 & 42,2 \\
\hline 46,531250 & 41,03 & 45 & 43,5 \\
\hline 51,539060 & 42,5 & 50 & 44,5 \\
\hline 56,546880 & 43,96 & 55 & 45,5 \\
\hline 61,546880 & 43,96 & 60 & 47 \\
\hline 66,546880 & 45,91 & 65 & 48 \\
\hline 71,546880 & 47,38 & 70 & 49 \\
\hline 76,546880 & 48,36 & 75 & 50 \\
\hline 81,546880 & 49,33 & 80 & 51 \\
\hline 86,546880 & 50,31 & 85 & 52 \\
\hline 91,546880 & 51,28 & 90 & 52,5 \\
\hline 96,546880 & 53,24 & 95 & 53,2 \\
\hline 101,546900 & 54,21 & 100 & 54,1 \\
\hline 106,546900 & 56,17 & 105 & 55 \\
\hline 111,546900 & 57,14 & 110 & 56 \\
\hline 116,562500 & 56,66 & 115 & 57,5 \\
\hline 121,562500 & 58,12 & 120 & 58,8 \\
\hline 126,562500 & 59,59 & 125 & 59,9 \\
\hline 131,562500 & 60,07 & 130 & 60,3 \\
\hline 136,562500 & 62,03 & 135 & 61,8 \\
\hline 141,562500 & 62,03 & 140 & 62,7 \\
\hline
\end{tabular}

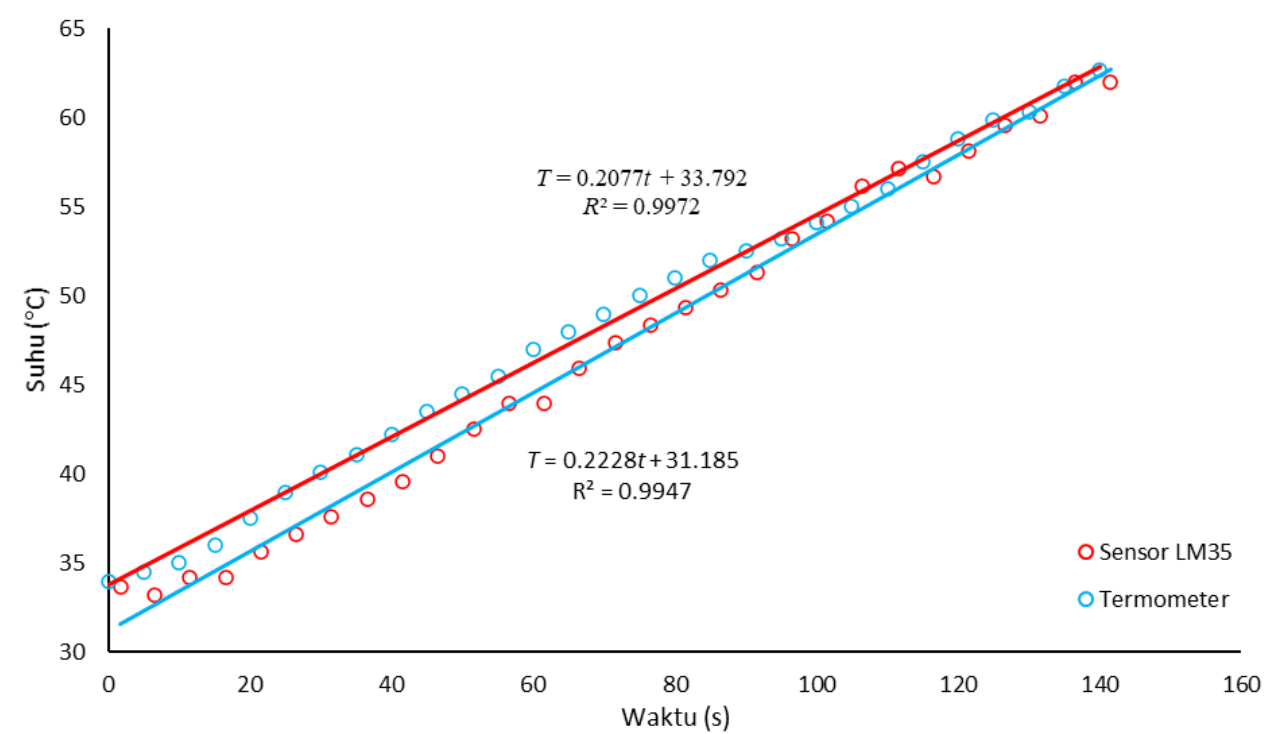

Gambar 6. Perubahan suhu sensor dan termometer 


\section{Simpulan}

Dari percobaan yang telah dilakukan dapat disimpulkan bahwa rancangan eksperimen sensor LM35 dapat mengukur perubahan suhu pemanasan alkohol. Perbandingan perubahan suhu yang diperoleh menggunakan probe sensor LM35 dan termometer tidak terlalu jauh sehingga alat eksperimen yang dibuat dapat digunakan dalam pembelajaran fisika dan sederhana dalam pembuatannya. Hasil yang diperoleh berupa akuisisi data dapat disimpan langsung ke dalam excel dengan menggunaan software PLX - DAQ. Perbandingan waktu yang dibutuhkan alkohol untuk mendidih dan kalor jenis alkohol tidak terlalu jauh dikarenakan pembacaan termometer ataupun perhitungan suhu dari LM35 yang kurang akurat. Hasil eksperimen ini menunjukan nilai ralat 1,324\% maka diperlukan kalibrasi sensor yang lebih akurat serta meningkatkan ketelitian saat pengambilan data. Agar data dapat dioptimalkan dan mendapat nilai ralat yang kecil kurang dari $1 \%$. Sehingga alat sederhana sensor LM35 yang dibuat sudah cukup memenuhi akurasi untuk mengukur suhu sebuah cairan.

\section{References}

Agustina, E. (2017). Uji aktivitas senyawa antioksidan dari ekstrak daun tiin (Ficus carica Linn) dengan pelarut air, metanol dan campuran metanol-air. Klorofil, 1(1), 38-47.

Azizah, N., Al-Baarri, A. N., \& Mulyani, S. (2012). Pengaruh lama fermentasi terhadap kadar alkohol, pH, dan produksi gas pada proses fermentasi bioetanol dari whey dengan substitusi kulit nanas. Jurnal Aplikasi Teknologi Pangan, 1(3), 72-77.

Berlian, Z., Aini, F., \& Ulandari, R. (2016). Uji kadar alkohol pada tapai ketan putih dan singkong melalui fermentasi dengan dosis ragi yang berbeda. Jurnal Biota, 2(1), 106-111.

Faizal, M., \& Wahyudi, F. (2017). Analisa pengaruh suhu dan waktu pemanasan pada nylon film terhadap mampu bentuk zipper. Bina Teknika, 13(1), 23-28.

Fraden, J. (2010). Handbook of modern sensors: Physics, designs, and applications (fourth). New York: Springer-Verlag.

Mustar, M. Y., \& Wiyagi, R. O. (2017). Implementasi sistem monitoring deteksi hujan dan suhu berbasis sensor secara real time. Semesta Teknika, 20(1), 20-28.

Novalina, P., Josua, A, S., Taslim, \& Herawan, T. (2015). Pengaruh variasi variabel reaksi pada proses ekstraksi reaktif mesokarp sawit untuk menghasilkan biodiesel. Jurnal Teknik Kimia USU, 4(4), 18-24.

Nurhayati. (2012). Rancang bangun alat pengontrol suhu berbasis mikrokontroler pada pembuatan bioetanol berbahan baku kulit pisang. Jurnal Teknik Elektro, 1(2), 47-53.

Prihandana, R., Noerwijari, Adinurani Setyaningsih, S., \& Hendroko. (2007). Fermentasi ubi kayu (manihot esculenta crantz) dan ubi jalar (ipomea batatas l. sin). Yogyakarta: Sunan Kalijaga.

Rahayuningtyas, A., Apriyanto, I. F., Kuala, S. I., \& Santoso, T. (2016). Pemanfaatan Lm35 sebagai sensor suhu otomatis pada sisem pengontrolan suhu ruangan pengering (Studi Kasus: Pengering Tipe Rak). ETHOS (Jurnal Penelitian dan Pengabdian), 4(1), 7-12.

Ridhuan, K., Irawan, D., Zanaria, Y., \& Firmansyah, F. (2019). Pengaruh jenis biomassa pada pembakaran pirolisis terhadap karakteristik dan efisiensi bioarang - asap cair yang dihasilkan. Media Mesin: Majalah Teknik Mesin, 20(1), 18-27.

Santi, S. S. (2008). Pembuatan alkohol dengan proses fermentasi buah jambu. Jurnal Penelitian Ilmu Teknik, 8(2), 104-111.

Sari, U., \& Kirindi, T. (2019). Using arduino in physics teaching: Arduino-based physics experiment to study temperature dependence of electrical resistance. Journal of Computer and Education Research, 7(14), 698710.

Suoth, V. A., Santoso, D. R., \& Maryanto, S. (2013). Pengembangan array sensor suhu dan sistem akusisi data berbasis mikrokontroler untuk pengukuran suhu bawah permukaan. Jurnal MIPA, 2(1), 66-72. 
Tambak, T. P., \& Bahriun, T. A. (2015). Perancangan sistem home automation berbasis arduino uno. Singuda ENSIKOM, 10(28), 121-126. 